Christophe Milési

Julien Baleine

Stefan Matecki

Sabine Durand

Clémentine Combes

Aline Rideau Batista Novais

Gilles Combonie

\title{
Is treatment with a high flow nasal cannula effective in acute viral bronchiolitis? A physiologic study
}

e-mail: c-milesi@chu-montpellier.fr

Tel.: +33-467-336609

Fax: +33-467-336228

Abstract Purpose: The high flow nasal cannula (HFNC) has recently been proposed to support infants with respiratory syncytial virus (RSV)related respiratory distress. However, in this disease, no physiologic data are currently available on the effects of this device. We assessed the capacity of HFNC to generate positive airway pressure, as well as the resulting effects on breathing pattern and respiratory effort. Meth-

ods: Twenty-one infants less than 6 months old with acute RSV bronchiolitis were studied prospectively in the pediatric intensive care unit of a university hospital. Pharyngeal pressure (PP) and esophageal pressure (Pes) were measured simultaneously at four increasing flows of 1, 4, 6 and $7 \mathrm{~L} / \mathrm{min}$ delivered through HFNC. Results: The PP was correlated with flow rate $(r=0.65, p \leq 0.0001)$, reaching mean and end-expiratory values of, respectively, 4 (95\% CI
3-5) $\mathrm{cmH}_{2} \mathrm{O}$ and $6.5(95 \% \mathrm{CI}$

5-8) $\mathrm{cmH}_{2} \mathrm{O}$ at $7 \mathrm{~L} / \mathrm{min}$. A

flow $\geq 2 \mathrm{~L} / \mathrm{kg} / \mathrm{min}$ was associated with the generation of a mean pharyngeal pressure $\geq 4 \mathrm{cmH}_{2} \mathrm{O}$ with a sensitivity of $67 \%$, a specificity of $96 \%$, a positive predictive value of $75 \%$, and a negative predictive value of $94.5 \%$. Only flows $\geq 6 \mathrm{~L} / \mathrm{min}$ provided positive PP throughout the respiratory cycle. From baseline to maximal flow rate, breathing frequency $(p<0.01), T_{\mathrm{i}} / T_{\text {tot }}(p<0.05)$, Pes swing $(p<0.05)$ and PTPes insp $\min (p<0.01)$, an index of respiratory effort, were reduced.

Conclusions: HFNC with a flow rate equal to or above $2 \mathrm{~L} / \mathrm{kg} / \mathrm{min}$ generated a clinically relevant PP, with improved breathing pattern and rapid unloading of respiratory muscles, in young infants with acute RSV bronchiolitis.

Keywords Acute viral bronchiolitis . High flow nasal cannula - Infant .

Respiratory distress ·

Respiratory syncytial virus infections

371 Avenue Du Doyen G. Giraud,

34295 Montpellier Cedex 5, France

\section{Introduction}

Respiratory syncytial virus (RSV) bronchiolitis is the most common lower respiratory tract illness in infants [1]. Although most cases respond to supportive management only, 2-6\% of these patients are admitted to a pediatric intensive care unit (PICU) for evolving respiratory distress [2]. In these serious forms of the disease, inflammation and plugging of the airways result in severe obstruction, with markedly increased respiratory system resistance and air trapping [3,4]. The consequences are an excessive respiratory muscle load and adaptive changes in breathing pattern [4-6] likely to generate fatigue, hypoventilation, and respiratory failure because of the 
increased chest wall compliance and the immature pattern of ventilatory muscle fiber types in early infancy [7].

Several clinical studies have suggested that continuous positive airway pressure (CPAP) is beneficial in cases of acute viral bronchiolitis [8-10]. Modifications in ventilation can be observed, particularly an increase in expiratory time, which favors passive expiration $[4,6]$. However, the main interest of this technique is that it significantly reduces the load on the inspiratory muscles [4, 6, 11].Young infants, however, do not always tolerate nCPAP, which is also noisy [12] and may cause nasal trauma [13]. Heated, humidified, high flow nasal cannulae (HFNC) have thus recently been adopted in pediatrics, as an alternative to non-invasive positive pressure ventilation. The data are currently very limited and mainly restricted to the use of this device in infants with acute viral bronchiolitis, with two retrospective chart reviews reporting less recourse to intubation in infants under 2 years following HFNC implementation in the PICU $[14,15]$. Furthermore, the authors were able to demonstrate that HFNC clearly reduced respiratory and heart rates, suggesting improved alveolar ventilation. Several mechanisms have been proposed to explain how HFNC might relieve respiratory distress, including washout of nasopharyngeal dead space, reduction of inspiratory resistance, and optimal conditioning of the breathing gas [16].

Studies performed mainly in neonates [17-20] and adults [21] have shown the ability of high flow nasal cannulae (HFNC) to generate some increase in pharyngeal pressure (PP). Currently, there is no physiologic data on airway pressure generation, or work and pattern of breathing in infants with bronchiolitis treated with HFNC. The main objective of this study was thus to measure the pharyngeal pressure provided by HFNC, using flows ranging from 1 to $7 \mathrm{~L} / \mathrm{min}$, in infants less than 6 months old hospitalized in the PICU for RSV bronchiolitis. The secondary objective was to assess the effects of HFNC on the clinical signs of respiratory distress, breathing pattern and muscular respiratory effort.

\section{Methods}

This study was conducted in an eight-bed PICU at Montpellier University Hospital Center, between November 2011 and March 2012.

\section{Population}

All infants less than 6-month old hospitalized in the PICU were considered for inclusion, provided that the following conditions were met: (1) RSV bronchiolitis confirmed by enzyme immunoassay; (2) mild respiratory distress defined using the modified Wood's clinical asthma score
(m-WCAS) as $1<$ m-WCAS $<4$; (3) HFNC support, applied first or in transition from nasal continuous positive airway pressure (nCPAP); (4) absence of pneumothorax on chest radiograph; (5) absence of neuromuscular disease; (6) weekday admission during daytime hours (Monday through Friday, 8:30 am to $6: 30 \mathrm{pm})$; (7) authorization to perform the study signed by both parents.

\section{Management of RSV bronchiolitis}

On admission, the nurse first settled the infant in the semirecumbent $\left(30^{\circ}\right)$ position, aspirated nasopharyngeal secretions, and started cardiorespiratory monitoring, including pulse oximetry $\left(\mathrm{SpO}_{2}\right)$ and blood pressure measurement (IntelliVue MP70, Philips Medical Systems).

The nasal cannula was placed and the flow rate was set at $1 \mathrm{~L} / \mathrm{min}$, with $\mathrm{FiO}_{2}$ adjusted to reach an $\mathrm{SpO}_{2}$ between 94 and $98 \%$. A pacifier was systematically used to limit as much air leak as possible from the mouth [17, 22]. A chest X-ray and capillary blood gas measurement were performed at the end of this step. A $120 \mathrm{ml} / \mathrm{kg}$ venous perfusion was started. Apnea despite HFNC or nCPAP support was treated with caffeine, $20 \mathrm{mg} / \mathrm{kg}$ for the loading dose and $5 \mathrm{mg} / \mathrm{kg}$ for daily maintenance.

\section{High flow delivery and setting}

We used a heated humidified high flow delivery system (RT329 System with MR850 humidifier, Fisher and Paykel, Villebon, France) connected to an oxygen therapy nasal cannula (BC2745 and BC2755, Fisher and Paykel, Villebon, France). The outer diameter of the nasal prong was approximately half the diameter of the infant's nare. As this system was equipped with a pressure release valve set at $45 \mathrm{cmH}_{2} \mathrm{O}$ (Fisher and Paykel, Villebon, France), we first used a spirometer (Spiro+, Saime, Savigny, France) to verify that flow downstream to the valve was similar to that indicated on the gas source for the study flow range.

\section{Protocol}

After placement of the esophageal pressure probe, we observed a period of complete rest for $10 \mathrm{~min}$. Once the infant was quiet and breathing regularly, we recorded clinical and manometric data. Baseline measurements were made at a flow rate of $1 \mathrm{~L} / \mathrm{min}$, then flow was arbitrarily increased to 4, 6 and $7 \mathrm{~L} / \mathrm{min}$. At each step, we respected a stabilization period of $10 \mathrm{~min}$ before any measurement. 


\section{Clinical data}

The RR and m-WCAS scores were collected by an observer who was not involved in patient care and blind from the data of pressure measurements, performed by the physiologist (SM).

The m-WCAS is a composite score that includes cyanosis, inspiratory breath sounds, accessory muscle use, expiratory wheezing, and cerebral function, with a visual analog scale used to standardize the scoring of accessory muscle use and wheezing. A detailed description of the score has been reported elsewhere [6].

\section{Pressure measurements}

Pressures were measured using a $1.3 \mathrm{~mm}$ diameter electronic pressure transducer (Gaeltec Devices Ltd., Isle of Skye, Scotland). Nasal insertion of the probe was performed after local anesthesia with lidocaine spray and always in the presence of the parents to comfort the infant.

The probe comprises two pressure sensors $10 \mathrm{~cm}$ apart. It was positioned with the proximal sensor in the pharynx, i.e., $7 \mathrm{~cm}$ after the nostril. Continuous on-line monitoring ensured that the distal probe remained in the middle portion of the esophagus by showing an oscillating signal with clear negative deflection simultaneous to inspiration on the screen.

Pharyngeal pressure (PP) and esophageal pressure (Pes) were recorded simultaneously (Fig. 1). The Pes swing was calculated from the Pes trace as the maximal variation in esophageal pressure generated by an inspiration. The pressure-time product per min $\left(\right.$ PTPes $_{\text {insp }} /$ min) was calculated from the Pes recording as the area under the pressure-time curve [23]. This area was quantified by scanning the surface, using the NIH image program, and calculated as the mean area under the Pes signal between the onset of the inspiratory effort and the end of inspiration (Pes dt). We then expressed PTPes insp per min by multiplying this averaged pressure-time product per breath by the breathing frequency $\left(\right.$ PTPes $_{\text {insp }}$ / $\min =$ Pes $\mathrm{dt} \times$ breathing frequency). Breathing pattern, including respiratory rate $(\mathrm{RR})$, inspiratory $\left(T_{\mathrm{i}}\right)$ and expiratory $\left(T_{\mathrm{e}}\right)$ time and $T_{\mathrm{i}} / T_{\text {tot }}$ ratio, were also determined from the Pes traces. The $T_{\mathrm{i}}$ was defined as the time between the onset and the end of the inspiratory effort. $T_{\text {tot }}$ was defined as the time between two consecutives onset of the inspiratory effort.

Data analysis

Quantitative variables were expressed as means (95\% CI). Qualitative variables were expressed in numbers and percentages. The qualitative variables were compared with the $\chi^{2}$ test. Spearman's correlation coefficient assessed the correlations between continuous variables. Repeated-measure analysis of variance with the Bonferoni correction compared the changes in clinical and manometric parameters over the course of the study. Significance was set at $5 \%$ for all tests. Statistical analysis was conducted with the SAS software package, version 9 (SAS Institute, Cary, NC).

\section{Ethical consideration}

We obtained signed informed consent from the parents of all infants, and the protocol was approved by the local ethics committee.

\section{Results}

Population

From December 2011 to March 2012, 38 infants presenting RSV bronchiolitis were admitted to the PICU. Seventeen of them were not eligible: 7 were managed during a weekend or a night, 6 had m-WCAS $<1$ soon after aspiration of secretions and were discharged from the unit within $24 \mathrm{~h}$, and 4 were older than 6 months.

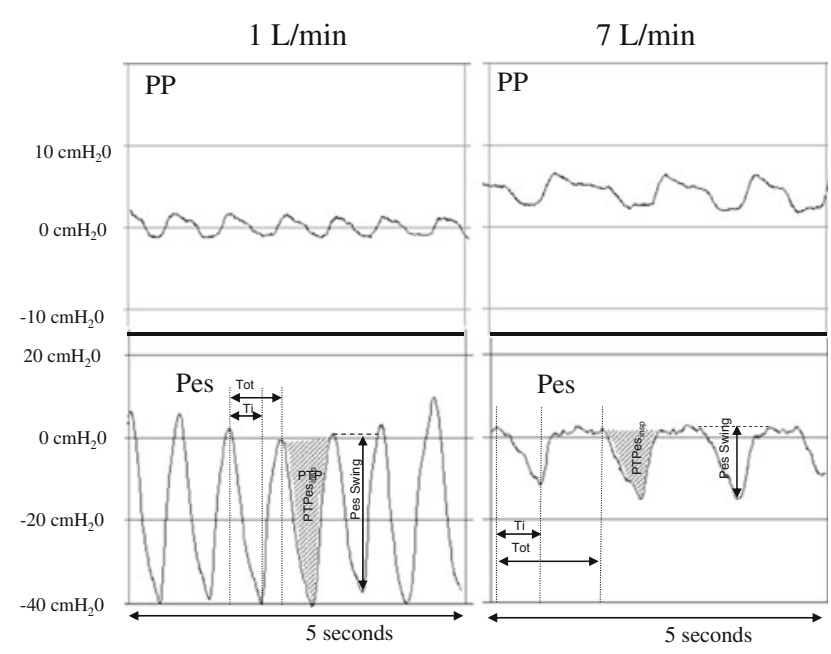

Fig. 1 Simultaneous recording of the pharyngeal pressure (PP) and the esophageal pressure (Pes) at 1 and $7 \mathrm{~L} / \mathrm{min}$ in an infant. From the Pes trace, Pes swing was measured as the maximal variation in esophageal pressure generated by an inspiration, and pressure-time product $\left(\right.$ PTPes $\left._{\text {insp }}\right)$ as the area under the pressure-time curve during inspiratory effort. Inspiratory $\left(T_{\mathrm{i}}\right)$, expiratory times and the ratio of the inspiratory time to the total time of the breathing cycle $\left(T_{\mathrm{i}} / T_{\text {tot }}\right)$ were also determined from the Pes traces (see "Methods" for details). The maximal flow, delivered by the nasal cannula, resulted in positive PP values during both inspiration and expiration and a dramatic decrease in Pes swings 
Overview of included patients

The 21 included patients were 1.5 (95\% CI 0.75-2.19) months old [range 0.5-6], and weighed 4.3 (95\% CI 3.6-4.9) kg [range 2.6-7.3].

One infant had been born prematurely at 35 weeks gestational age, and another term neonate had a birth weight $<2$ SD below the mean for gestational age. No patient had chronic lung disease, congenital cardiac disease or respiratory malformation.

It was the first episode of RSV bronchiolitis for all these infants. Three of them had received a nebulized $\beta$-adrenergic agent, and three others a corticosteroid treatment. These treatments were stopped on arrival at the pediatric emergency department, i.e., more than $24 \mathrm{~h}$ before enrollment, and were not administered during the study period.

Nine infants had been treated with caffeine for recurrent apnea, and antibiotics had been initiated in ten of them during the study.

\section{Baseline respiratory features}

In infants placed on $1 \mathrm{~L} / \mathrm{min}$, the mean baseline values were as follows: m-WCAS: 2.3 (95 \% CI 1.9-2.7), RR: 81 (95\% CI 73-88) breaths/min, $T_{\mathrm{i}} / T_{\text {tot }}: 0.44$ (95\% CI 0.38-0.48), $\mathrm{FiO}_{2}: 0.23(95 \% \mathrm{CI} \quad 0.21-0.26), \mathrm{SpO}_{2}: 96(95 \% \mathrm{CI}$ 95-97), and $\mathrm{PCO}_{2}: 52$ (95\% CI 46-58) torr. $\mathrm{PTPes}_{\text {insp }} / \mathrm{min}$ was 546 (95\% CI 395-696) $\mathrm{cm} \mathrm{H}_{2} \mathrm{O} / \mathrm{s} / \mathrm{min}$.

\section{PP generated by HFNC}

The mean PP increased from $0.2(95 \% \mathrm{CI}-0.2 \pm 0.7)$ $\mathrm{cmH}_{2} \mathrm{O}$ at $1 \mathrm{~L} / \mathrm{min}$ to $4\left(95 \%\right.$ CI 3-5) $\mathrm{cmH}_{2} \mathrm{O}$ at maximal flow $(p=0.0001)$. Mean PP and flow were correlated $(R=0.65, p<0.0001)$, but only flows $\geq 6 \mathrm{~L} / \mathrm{min}$ generated increases in PP resulting in positive pressure values during both inspiration and expiration. At each flow, expiratory PP was positive (Fig. 2). A correlation was observed between the weight-indexed flow rate $(\mathrm{L} / \mathrm{Kg} /$ $\min )$ and the generated PP $(R=0.77, p \leq 0.001)$. A flow $\geq 2 \mathrm{~L} / \mathrm{kg} / \mathrm{min}$ was associated with the generation of a mean pharyngeal pressure $\geq 4 \mathrm{cmH}_{2} \mathrm{O}$ with a sensitivity of $67 \%$, a specificity of $96 \%$, a positive predictive value of $75 \%$, and a negative predictive value of $94.5 \%$. The interindividual coefficient of variation of mean PP decreased from $77 \%$ at $4 \mathrm{~L} / \mathrm{min}$ to nearly $50 \%$ at $6 \mathrm{~L} / \mathrm{min}$ and maximal flow rate.

Effects of increasing nasal cannula flow rate on respiratory distress (Fig. $3 a, b)$

Increasing the flow from 1 to $7 \mathrm{~L} / \mathrm{min}$ resulted in significant reductions of $\operatorname{RR}(p=0.007)$ and m-WCAS $(p=0.0096)$. No change was observed for oxygen requirements $(p=0.28)$ or $\mathrm{SpO}_{2}(p=0.28)$.

Effects of increasing nasal cannula flow rate on breathing pattern and respiratory effort $($ Fig. $3 c, d)$

Compared with $1 \mathrm{~L} / \mathrm{min}, T_{\mathrm{i}} / T_{\text {tot }}$ was lower $(p=0.02)$, Pes swing decreased $(p=0.04)$, and PTPes insp $_{\text {inin }}$ $(p=0.007)$ was also reduced at maximal flow rate. The decreases in Pes and PTP were correlated with an increase in $\mathrm{PP}(R=0.38, p=0.0097$ and $R=0.418, p=0.0038$, respectively).

Patient outcomes

On average, HFNC was maintained for $62(95 \% \mathrm{CI}$ 39-85) h, 96 (95\% CI 22-170) h for those placed directly on the cannula and 52 (95\% CI 36-70) $\mathrm{h}$ for those who transitioned to HFNC from nCPAP; $p=0.26$.

No infant placed under HFNC presented complications, particularly air leak syndrome, and none required backup treatment with nCPAP or intubation. The hospital stay was 4.5 (95\% CI 3.6-5.3) days.

\section{Discussion}

In young infants with RVS bronchiolitis, use of a nasal cannula with a flow rate of $7 \mathrm{~L} / \mathrm{min}$ was able to generate positive mean PP throughout the respiratory cycle. This increase resulted in an approximately $50 \%$ reduction in respiratory effort and rapid improvement in the moderate respiratory distress of these patients.

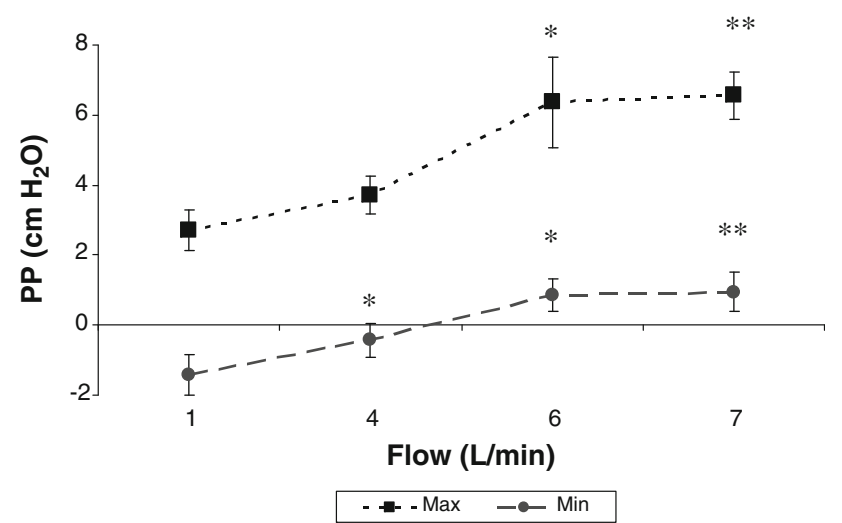

Fig. 2 Maximum (Max) and minimum (Min) pharyngeal pressure (PP) amplitude generated by the high flow nasal cannula (HFNC), using flows ranging from 1 to $7 \mathrm{~L} / \mathrm{min} .{ }^{*} p<0.05$, $* * p<0.01$ vs $1 \mathrm{~L} / \mathrm{min}$ 
Fig. 3 Effects of increasing flow rates on clinical signs of respiratory distress, breathing pattern and muscular respiratory effort. a Change in respiratory rate (RR). b Change in the respiratory distress score, the modified Wood clinical asthma score (m-WCAS). c Change in the ratio of the inspiratory time to the total respiratory cycle time $\left(T_{\mathrm{i}} / T_{\text {tot }}\right) \mathbf{d}$ Change in an index of respiratory effort, the inspiratory muscle pressuretime product per min (PTPes $\left._{\text {insp }} / \mathrm{min}\right) . * p<0.05$, $* * p<0.01$ vs $1 \mathrm{~L} / \mathrm{min}$
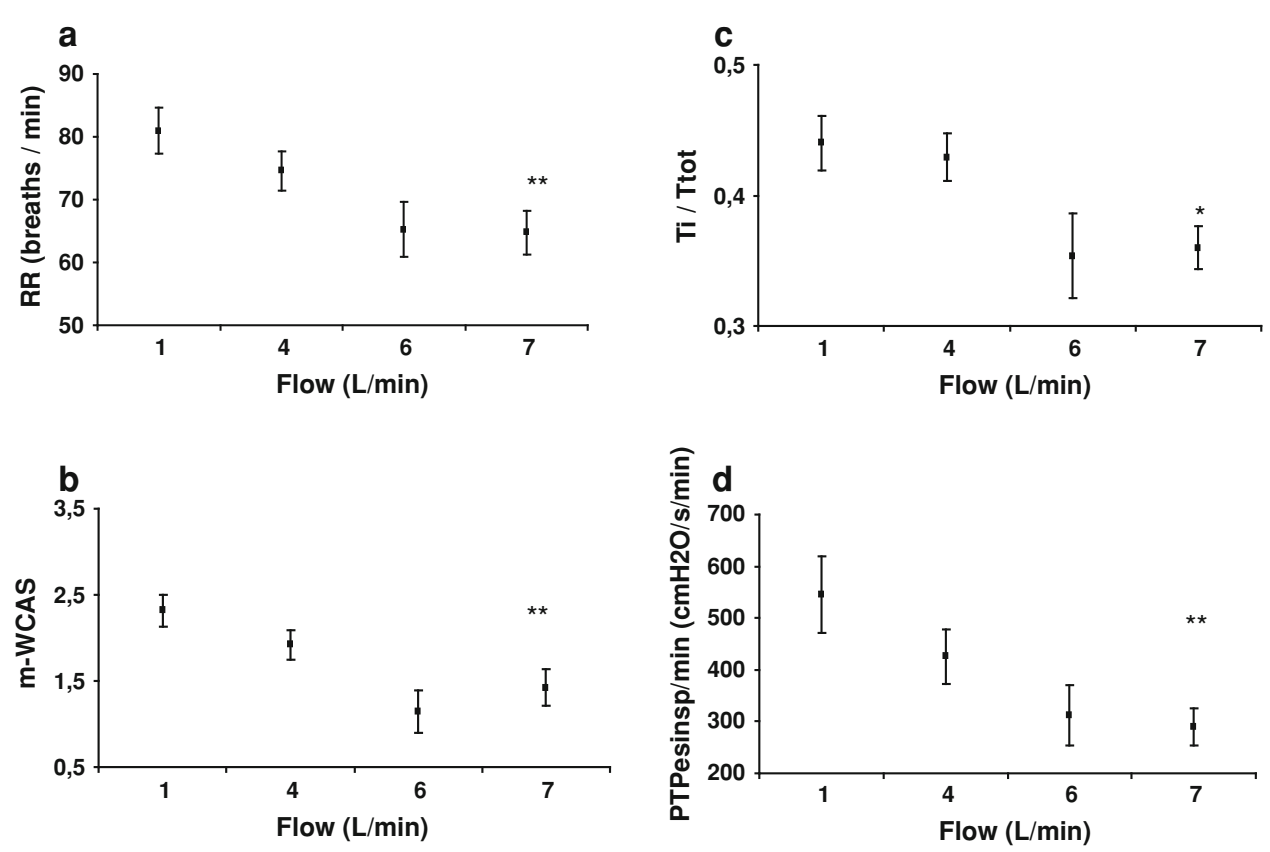

What this study adds

In acute viral bronchiolitis, the predominant mechanism to rapidly alleviate the dramatic increase in work of breathing is to supply a degree of positive airway pressure $[6,11]$. Spentzas et al. [24] first measured PP in a heterogeneous population of neonates and children with nonspecific respiratory distress, following application of flows eight to ten times the normal min ventilation, through a nasal cannula. As RSV bronchiolitis is the leading cause of respiratory distress in young infants and the use of HFNC is increasing for this disease, we believed it would be important to determine the actual PP achieved with this device and its consequences on breathing pattern and respiratory effort in this context. The correlation between weight-indexed flow rate and the generated PP may help clinicians on how to titrate flow in a patient. The correlations were weaker with breathing pattern and respiratory muscle effort, but this study allowed us to determine the optimal flow required to reach the target PP, i.e., associated with an improved clinical status that could objectively be attributed to the reduction in respiratory work. The findings from this physiologic study may guide the formulation of hypotheses for future randomized control studies focused on clinical outcomes like intubation rate, length of stay, and safety.

\section{Air leak control: the cornerstone of HNFC efficacy}

The PP is greatly affected by air leaks that occur around the nasal cannula and by mouth [16-22]. Two strategies were deployed to minimize them. The first was to keep the mouth closed with a pacifier. The second was the use of nasal prongs of sufficient diameter, i.e., at least half the diameter of the infant's nare. As we had only two prong sizes at our disposal, we speculate that nasal air leaks were the main reason for the large interindividual variations in PP. However, the main difficulty of using HFNC is not obtaining a positive mean PP, but rather keeping the pressure positive throughout the respiratory cycle. With a fixed flow, HFNC generates a variable PP that can remain negative through part or all of inspiration if the HFNC flow is lower than the patient's inspiratory demand. Such a flow is particularly difficult to determine in children under 3 years [25]. Whereas the mean PP was positive from $4 \mathrm{~L} / \mathrm{min}, 6 \mathrm{~L} / \mathrm{min}$ was necessary to also obtain positive PP during inspiration, thus switching the ventilatory support feature from spontaneous ventilation with positive end-expiratory pressure (SV-PEEP) to spontaneous ventilation with continuous positive airway pressure (SV-CPAP). On the other hand, we found no correlation between PP and weight. The constitution of a homogeneous population, with limited age and weight ranges, and the adaptation of the nasal prong size to the patient's anatomy, probably explain why we did not confirm the inverse relationship between PP and weight reported previously $[17,24]$.

HFNC in acute viral bronchiolitis: how does it work?

In our patients, HFNC immediately resulted in increased expiratory time and decreased inspiratory work, suggesting that this support may offset the patient's inspiratory 
effort to overcome PEEPi. Overpowering PEEPi, and thereby decreasing the dynamic collapse of the very compliant airways at this young age, could be the main benefit of HFNC, since we constantly measured positive PP during expiration, whatever the flow rate. Precise measurement of PEEPi was not performed in this study because it requires airflow monitoring with face-mask pneumotachography, which in our experience is poorly tolerated in this clinical situation.

\section{Limitations}

Our empiric protocol for RSV bronchiolitis management led us to investigate some infants treated primarily with HFNC and others after nCPAP. The results were comparable in these two subgroups, although they may have represented different phases or severity in the disease. As in previous studies on this topic [19-21], we used a progressive increase in flow rate because this design is easier to carry out at bedside. Randomizing the flow rate sequence might have been more rigorous to control for detection bias.

Other limitations were the small sample size and the physiologic nature of the main criteria for evaluation. Pharyngeal and esophageal pressures were recorded using a nasal probe, because the infant's tolerance during insertion was better than with an oral probe, which we initially tried and rapidly abandoned. Partial obstruction of the upper airways with a nasal probe may compromise respiratory function and, more precisely, increase airway resistance [26]. Consequently, our measurements mainly illustrated the improvement in respiratory effort following HFNC, rather than providing data on the actual work of breathing in infants with RSV-related mild respiratory distress. The probe was also kept in place for a short period, for only the time needed to determine the optimal flow rate for each child. However, Shibler et al. demonstrated that HFNC-related changes, such as a decrease in the respiratory rate, occurred very early and remained stable thereafter [15].

Several high flow delivery systems are available. Between devices, differences in nasal cannula and the presence of a pressure release valve may theoretically affect airway pressure generation [27]. Ours was equipped with a valve that limited the flow rate to $7 \mathrm{~L} / \mathrm{min}$. It would be interesting to use other devices to assess the ability to generate higher degrees of positive pressure, which might be more effective in severe forms of the disease [4].

\section{Conclusion}

HFNC with a flow rate equal to or above $2 \mathrm{~L} / \mathrm{kg} / \mathrm{min}$ generated a clinically relevant PP, i.e., a mean $\mathrm{PP} \geq 4 \mathrm{cmH}_{2} \mathrm{O}$, with improved breathing pattern and rapid unloading of respiratory muscle in young infants with acute RSV bronchiolitis.

\section{References}

1. American Academy of Pediatrics Subcommittee on Diagnosis and Management of Bronchiolitis (2006) Diagnosis and management of bronchiolitis. Pediatrics 118:1774-1793

2. Welliver RC (2003) Review of epidemiology and clinical risk factors for severe respiratory syncytial virus (RSV) infection. J Pediatr 143:S112S117

3. Hammer J, Numa A, Newth CJ (1997) Acute respiratory distress syndrome caused by respiratory syncytial virus. Pediatr Pulmonol 23:176-183

4. Essouri S, Durand P, Chevret L, Balu L, Devictor D, Fauroux B, Tissières $P$ (2011) Optimal level of nasal continuous positive airway pressure in severe viral bronchiolitis. Intensive Care Med 37:2002-2007

5. Stokes GM, Milner AD, Groggins RC (1981) Work of breathing, intrathoracic pressure and clinical findings in a group of babies with bronchiolitis. Acta Paediatr Scand 70:689-694
6. Cambonie G, Milési C, Jaber S, Amsallem F, Barbotte E, Picaud JC, Matecki S (2008) Nasal continuous positive airway pressure decreases respiratory muscles overload in young infants with severe acute viral bronchiolitis. Intensive Care Med 34:1865-1872

7. Muller NL, Bryan AC (1979) Chest wall mechanics and respiratory muscles in infants. Pediatr Clin N Am 26:503-516

8. Beasley JM, Jones SE (1981) Continuous positive airway pressure in bronchiolitis. Br Med J (Clin Res Ed) 283:1506-1508

9. Thia LP, McKenzie SA, Blyth TP, Minasian CC, Kozlowska WJ, Carr SB (2008) Randomised controlled trial of nasal continuous positive airways pressure (CPAP) in bronchiolitis. Arch Dis Child 93:45-47
10. Javouhey E, Barats A, Richard N, Stamm D, Floret D (2008) Noninvasive ventilation as primary ventilatory support for infants with severe bronchiolitis. Intensive Care Med 34:1608-1614

11. Milési C, Matecki S, Jaber S, Mura T, Jacquot A, Pidoux O, Chautemps N, Novais AR, Combes C, Picaud JC, Cambonie $\mathrm{G}$ (2012) $6 \mathrm{~cm} \mathrm{H}_{2} \mathrm{O}$ positive airway pressure versus conventional oxygen therapy in severe viral bronchiolitis: a randomized trial. Pediatr Pulmonol. doi: 10.1002/ppul.22533

12. Surenthiran SS, Wilbraham K, May J, Chant T, Emmerson AJ, Newton VE (2003) Noise levels within the ear and post-nasal space in neonates in intensive care. Arch Dis Child Fetal Neonatal Ed 88:F315-F318

13. Robertson NJ, McCarthy LS, Hamilton PA, Moss AL (1996) Nasal deformities resulting from flow driver continuous positive airway pressure. Arch Dis Child Fetal Neonatal Ed 75:F209-F212 
14. McKiernan C, Chua LC, Visintainer PF, 19. Spence KL, Murphy D, Kilian C, Allen H (2010) High flow nasal cannulae therapy in infants with bronchiolitis. J Pediatr 156:634-638

15. Schibler A, Pham TM, Dunster KR, Foster K, Barlow A, Gibbons K, Hough JL (2011) Reduced intubation rates for infants after introduction of high-flow nasal prong oxygen delivery. Intensive Care Med 37:847-852

16. Dysart K, Miller TL, Wolfson MR, Shaffer TH (2009) Research in high flow therapy: mechanisms of action. Respir Med 103:1400-1405

17. Kubicka ZJ, Limauro J, Darnall RA (2008) Heated, humidified high-flow nasal cannula therapy: yet another way to deliver continuous positive airway pressure? Pediatrics 121:82-88

18. Lampland AL, Plumm B, Meyers PA, Worwa CT, Mammel MC (2009)

Observational study of humidified highflow nasal cannula compared with nasal continuous positive airway pressure. J Pediatr 154:177-182
McGonigle R, Kilani RA (2007) Highflow nasal cannula as a device to provide continuous positive airway pressure in infants. J Perinatol 27:772-775

20. Wilkinson DJ, Andersen CC, Smith K, Holberton J (2008) Pharyngeal pressure with high-flow nasal cannulae in premature infants. J Perinatol 28:42-47

21. Parke R, McGuinness S, Eccleston M (2009) Nasal high-flow therapy delivers low level positive airway pressure. $\mathrm{Br} \mathrm{J}$ Anaesth 103:886-890

22. Dani C, Pratesi S, Migliori C, Bertini G (2009) High flow nasal cannula therapy as respiratory support in the preterm infant. Pediatr Pulmonol 44:629-634

23. Collett PW, Perry C, Engel LA (1985) Pressure-time product, flow, and oxygen cost of resistive breathing in humans. J Appl Physiol 58:1263-1272

24. Spentzas T, Minarik M, Patters AB, Vinson B, Stidham G (2009) Children with respiratory distress treated with high-flow nasal cannula. J Intensive Care Med 24:323-328
25. Vilozni D, Efrati O, Barak A, Yahav Y, Augarten A, Bentur L (2009) Forced inspiratory flow volume curve in healthy young children. Pediatr Pulmonol 44:105-111

26. Martin RJ, Miller MJ, Siner B, DiFiore JM, Carlo WA (1989) Effects of unilateral nasal occlusion on ventilation and pulmonary resistance in infants. J Appl Physiol 66:2522-2526

27. Hasan RA, Habib RH (2011) Effects of flow rate and airleak at the nares and mouth opening on positive distending pressure delivery using commercially available high-flow nasal cannula systems: a lung model study. Pediatr Crit Care Med 12:e29-e33 